\title{
APPLYING CBA TO DECIDE THE BEST EXCAVATION METHOD: SCENARIO DURING THE COVID-19 PANDEMIC
}

\author{
Lisseth R. Espinoza ${ }^{1}$, Xavier Brioso ${ }^{2}$, and Rodrigo F. Herrera ${ }^{3}$
}

\begin{abstract}
On January 30 of 2020, The World Health Organization declared the pandemic crisis as the first public emergency with international importance. Because of this, many building projects were paralyzed since then and the building industry experienced changes that have brought the inclusion of new tools to achieve the objectives of the projects. The purpose of the present paper is to present the application of Choosing By Advantages (CBA) methodology to select the best alternative in the material removal system in the execution of basements in a project that was paralyzed by the health emergency COVID19. CBA is a lean tool used to make decisions with clarity and transparency and in this case is used to consider the constraints of COVID-19 protocol to guide in decisions making. This methodology was applied to a case study for a building project in the basement construction phase that restarts its activities in the excavations. For that, an expert panel was formed to analyze and decide the best alternative solution. Finally, the selected alternative was implemented on-site, validating the methodology. It is concluded that CBA is an excellent tool to transparently document the selection process of the removal system. Additionally, this methodology allows including activities regarding the COVID-19 protocol, without affecting the project's productivity.
\end{abstract}

\section{KEYWORDS}

Lean construction, Choosing by Advantages (CBA), decision-making, excavations, COVID-19.

\section{INTRODUCTION}

In March 2020, the coronavirus pandemic reached all the nations worldwide; it was declared a global pandemic by the World Health Organization (2020). This fact disrupted and put risk industries in the entire world, including the construction industry (Ogunnusi et al. 2021; Alsharef et al. 2021). Given this fact, building projects were paralyzed in the middle of the execution process, affecting the time, costs, and resources. This problem leads to building companies making important decisions in order to recover the initially planned term. On the other hand, in the construction industry, decision-making at any stage of the project is of utmost importance to increase value (Juan et al. 2017). However,

Research, Catholic University of Santa Maria, Arequipa, Peru, rocioespinozataype@ gmail.com, orcid.org/0000-0001-5038-0863

2 Professor, GETEC Research Group, Department of Engineering, Pontifical Catholic University of Peru, Lima, xbrioso@ pucp.edu.pe, orcid.org/0000-0002-0174-0241

3 Professor, School of Civil Engineering, Pontificia Universidad Católica de Valparaiso, Valparaiso, Chile, rodrigo.herrera@ pucv.cl, orcid.org/0000-0001-5186-3154 
traditionally, the decision-making of an alternative is carried out empirically, based first on the experience of expert judgment, second on the analysis of the budget available for said activity, and finally on the search for an alternative that meets the above and the customer's preference.

Choosing By Advantages (CBA) is a tool that helps decision-making based on relevant facts (Arroyo et al. 2013). CBA is used to make multiple decisions in the building project life cycle (Brioso et al. 2019); however, there are still no publications that explain its use during the COVID-19 pandemic in the excavation phase. The use of CBA during the pandemic is relevant, since it is part of a solution to the variability in the execution period, being that during the pandemic this problem worsens. This application guides on how to anticipate complex and unlikely situations in the future, such as the COVID-19 pandemic. The purpose of this work is to introduce the method CBA for decision-making of the best alternative in surplus material removal systems in basement construction and applying it to a real case study during the pandemic. With this application it is possible to document and formalize relevant data of the material removal system, making a decision based on important criteria for the context in which the project is located. In this case study, the effects of the pandemic could be positive as well as negative. Positive, because it was necessary to use alternatives of novel methods to avoid the virus spreading (Afkhamiaghd and Elwakil 2020). These alternative methods consider factors such as productivity, interferences with other areas, installation time, facility of installation, occupation area.

\section{LITERATURE REVIEW}

\section{Choosing by Advantages (CBA)}

CBA was initially developed by Jim Suhr. CBA is a form of multi-criteria decision analysis (MCDA), although it was found to be superior to other MCDA methods (Suhr 1999). CBA encourages the use of correct data by basing decisions on anchor questions, relevant facts, and significance of the differences between the advantages of the alternatives (Suhr 1999). When implementing the CBA method, the steps are followed:

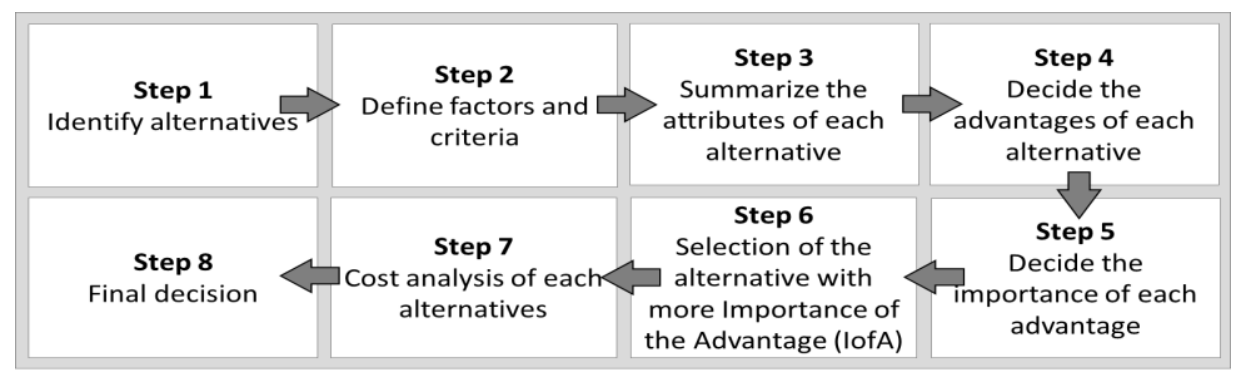

Figure 1. Steps to CBA method (Arroyo et al. 2013; Brioso et al. 2019).

CBA employs the following vocabulary: (1) alternative: a possible option; (2) criterion: a mandatory decision rule or desired guideline; (3) attribute: a feature or quality of a particular alternative; (4) advantage: a benefit-conferring difference between two and only two attributes; (5) factor: an "umbrella" concept, which includes the other concepts in the process; and (6) importance of an advantage: a degree of importance is assigned to each advantage for purposes of comparison. (Suhr 1999; Parrish and Tommelein 2009). CBA makes the decision-making process more transparent and provides a starting point for future work when faced with similar decisions. This makes it possible that the 
knowledge captured in the CBA table can be useful in the future. (Parrish and Tommelein 2009).

Some studies compare CBA with other methods. Arroyo et al. (2012) explored the characteristics that make a method viable and those that disqualify it, the authors compared and contrasted value-based methods versus CBA, and finally concluded that CBA produces fewer conflicting questions than other choice methods. The same author presented a case study comparing the use of Weighting Rating and Calculating (WRC) versus CBA in selecting a structural system for a residential building on a campus in Palo Alto, California. The case study found that the same decision resulted from both methods, but CBA helped create transparency and generate consensus on the rationale for the decision (Arroyo et al. 2014)

Other studies explored CBA to select an alternative. Parrish and Tommelein (2009) explored the use of CBA to select a design for steel reinforcement in a beam-column joint, this study showed that the values of the team members can conflict, without However, including all perspectives in the CBA table enriches the decision-making process. Martinez et al. (2016) used the CBA to choose the best formwork system, since traditionally they are selected based on the individual experience of the contractors. Karakhan et al. (2016) used CBA to make safety design decisions. Suarez et al. (2020) used CBA to compare 5D BIM models (integrated quantities, costs and schedules), flow lines (Location Based Management System scheduling system and CPM models (3D and 4D).

While other studies integrated CBA with other methods. Chauhan et al. (2019) applied CBA together with cost-benefit analysis to define a process for measuring the impact of prefabrication. Perez and Arroyo (2019) focused on analysing the environmental public policy design process using the CBA decision system integrated with the Design Structure Matrix (DSM) to make complex decisions. Brioso and Calderón-Hernández (2019) in a study aimed to improve the Scoring system with the elements of CBA and describe a teaching strategy applied in a Civil Engineering school. In conclusion, the authors recommended the inclusion of elements of the CBA in the general framework of the Scoring system, to create greater transparency and reduce the time to reach a consensus. The same author Brioso et al. (2019) integrated IVR with CBA in the selection of a fall protection system, with the aim of increasing transparency. On the other hand, Schöttle et al. (2019) use CBA to empower people in an organization and include them in the decision-making process, the author found evidence that CBA promotes inclusion to overcome groupthink and promotes psychological safety.

\section{CBA BENEFITS}

Among the benefits that CBA provides are the following: (1) It Generates transparency in the decision-making process and allows explicit consideration of multiple alternatives based on various impact factors (Parrish and Tommelein 2009; Arroyo et al. 2012; Chauhan et al. 2019; Arroyo et al. 2014). (2) It helps generate consensus based on the decision and promotes continuous learning (Parrish and Tommelein 2009; Arroyo et al 2012; Chauhan et al. 2019; Arroyo et al. 2014). (3) It helps to document information on why and on what basis decisions are made, so that they can be reviewed at a later time or in a future project (Parrish and Tommelein 2009). (4) It includes all perspectives of those involved, allowing multidisciplinary participation (Parrish and Tommelein 2009; Abraham et al. 2013; Karakhan et al. 2016). (5) CBA unlike other methods of decision analysis produces fewer questions conflicting, and allows the project team to discuss 
based on what they really value (Arroyo et al. 2012). (6) CBA Enables early participation and collaboration among stakeholders (Arroyo et al. 2012; Karakhan et al. 2016). (7) CBA deliver value to stakeholders and to the same time reducing uncertainty in the decision-making process, which will reduce the amount of waste generated incorrect decisions (Arroyo et al. 2012). (8) CBA Promotes stakeholder inclusion and promotes psychological safety (Schöttle et al. 2019). (9) It generates a social process in which the debate, argumentation and rhetoric played a role in the final resolution (Martinez et al. 2016). (10) CBA Helps decision makers to represent the context of their case, leading them to select the alternative that best suited the characteristics of their project (Martinez et al. 2016). (11) CBA generates an effective analysis and comparison of alternatives (Suarez et al. 2020). (12) Witch CBA the results of alternatives are easy to analyse, identifying the advantages, the factors in which is the difference and offer clearness to the criteria (Cortes et al. 2017).

\section{COVID-19 PRotocol}

In Peru, the COVID-19 protocol for building works was promulgated on May 8, 2020 (MCVS 2020). It likewise adopts actions indicated in the ministerial resolution of the Ministry of Health in Peru (MINSA 2020). Through this document is disseminating actions required to start or restart building projects. The protocol contains obligations stipulated. 1) Prepare a plan for the surveillance of the prevention and control of COVID19. 2) Demand the mandatory use of masks. 3) Carry out a discard evaluation of all people at the entrance and exit of the work (control temperature and pulse oximetry). 4) Subscribe to the COVID-19 symptomatology file for anyone who returns to work. 5) Install information panels with basic recommendations; maintain a safety distance of $1.5 \mathrm{~m}$ during the stay in work, disinfect with periodicity every environment, and restrict the meetings that generate crowds, providing a space for dining room with a reduced capacity may be in shifts. Likewise, establish areas destined for previous control, topic, changing rooms, lavatories, among other actions described in the protocol. All these actions to face COVID-19 modify the work production systems in building companies.

\section{RESEARCH METHOD}

This research adopted a CBA tabular method model, that consists of 8 steps for its implementation. The case study protocol is show in Figure 2:

\begin{tabular}{|c|c|c|c|}
\hline & CASE STUDY & Aplication CBA & \\
\hline $\begin{array}{l}\text { LITERATURE } \\
\text { REVIEW } \\
>\text { What is } \\
\text { CBA? } \\
>\text { CBA } \\
\text { Benefit } \\
>\text { Protocol } \\
\text { COVID-19 }\end{array}$ & $\begin{aligned} & \text { Object for the decision } \\
&>\text { Excavation method } \\
& \text { Selection of the expert panel } \\
&>\text { Project team } \\
&>\text { Experience in the } \\
& \text { construction of basements } \\
&>\text { knowledge of CBA tool }\end{aligned}$ & $\begin{array}{l}\text { Step 1: Identify alternatives } \\
\text { Step 2: Define factors and criteria } \\
\text { Step 3: Summarize the attributes of each alternative } \\
>\text { Step 4: Decide the advantages of each alternative } \\
>\text { Step 5: Decide the importance of each advantage } \\
>\text { Step 6: Selection of the alternative with more } \\
\text { Importance of the Advantage (lofA) } \\
>\text { Step 7: Cost analysis of each alternatives } \\
>\text { Step 8: Final decision }\end{array}$ & $\begin{array}{l}\text { Implement } \\
\text { alternative }\end{array}$ \\
\hline
\end{tabular}

Figure 2. The case study protocol

\section{CASE STUDY}

The case study is a building project destined for offices located in Lima-Peru. It involves constructing nine basements, destined for parking lots and warehouses, and once floors destined for offices. This project is characterized by its deep excavation of up to $30.55 \mathrm{~m}$, 
with a land area of $1,487.65 \mathrm{~m}^{2}$. This project involves the construction of 350 panels of anchored walls. The duration of this activity is approximately nine months.

The project was paralyzed at the beginning of the excavations (on March 15, 2020). The national state of emergency was declared due to the serious circumstances that affected and continue affecting life as a result of the COVID-19 outbreak (PCM 2020). Under these circumstances, as part of the building project restart, the building company used the Last Planner System (LPS) where collaborative planning was carried out with the team in order to redraft activities in this phase. In this context, it the necessary to choose an adequate method to remove material in the deepest basements excavations not to harm the project deadline. Regarding eliminating the first seven basements, the ramp conformation was used, and a platform with two backhoes, which work satisfactorily (Guio and Cayllahua 2019). For the seventh, eighth, and ninth basements, the best alternative had to be decided, this being the object of this study. To decide the best alternative in advance, it was decided to apply the Lean Construction CBA tool. For this, the perspectives of the expert group were integrated, based on scenarios and early collaboration (Parrish and Tommelein 2009; Arroyo et al. 2013).

\section{RESULTS AND DISCUSSIONS}

\section{OBJECT FOR THE DECISION}

In the construction of conventional buildings, there are 4 main phases in its construction stage: (1) substructure (includes basements), (2) superstructure, (3) wet and dry finishes, next to the facilities and finally (4) exterior works and furniture installation. Each of these phases has takt-time planning, so taking advantage of some of these phases is crucial for the project in terms of time. One of the phases with the possibility of gaining an advantage is the substructure phase, especially in the material removal activity when choosing an effective removal system. It's so the advantage that has been taken in this phase is directly proportional to the fulfillment of the final project deadline.

In this case study, will be analyzed the material removal from the sixth to the ninth basement, in view of this activity is a bottleneck that blocks the substructure phase's takttime, impairing the fulfilment of the drilling and the concreting of anchored walls. The origin of this bottleneck has two reasons. Firstly, the little space in the land area, since the zones designated for temporary areas grew to give space for areas such as topical, dining room, sinks and dressing rooms with the $1.5 \mathrm{~m}$ distance, spaces planned as part of the Plan of the prevention and control of COVID-19. And secondly, the set of materials to be removed is supported in an area that needs to continue with the planning.

\section{SElection of THE EXPERT PANel}

The criteria for the selection of the panel of experts, first is that they are part of the project team. The expert team was constituted by the project manager, field engineer, safety engineer, and costs engineer. Second that the group of experts have experience in these building types (edifications with several basements and floors). And finally that they have some knowledge of the CBA tool. This last criterion is met since the project team previously received training on the philosophy and tools Lean from the company.

\section{Aplication CBA}

\section{Step 1: Identify Alternatives}

The expert panel identified three alternatives. 1) Removal by conveyor belt anchored in walls (Figure 4.A). 2) Conveyor belt without anchoring in walls (Figure 4.B). 3) The 
vertical lifting system (Figure 4.C). For this building project, the expert's panel determined that the minimum material to be removed should be $400 \mathrm{~m}^{3}$ per day to ensure the advance of the scheduled takt-time of the anchored walls.

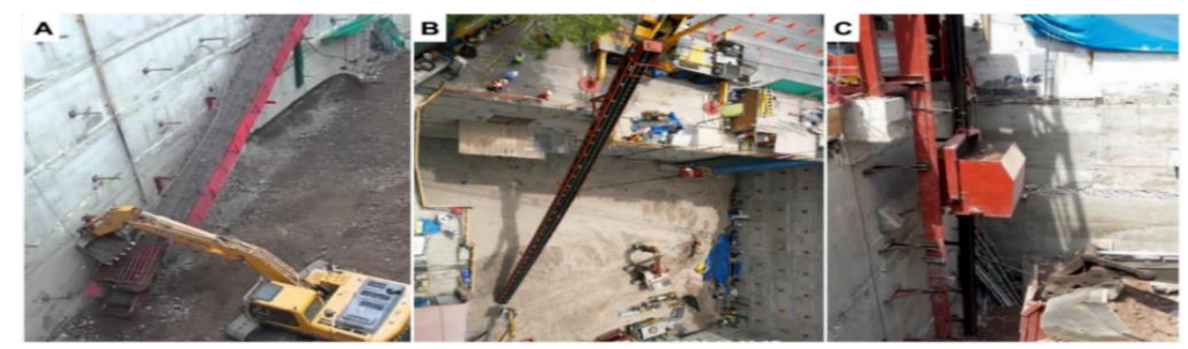

Figure 4: Alternatives to remove material for the seven, eight and nine basements.

\section{Step 2: Define factors and criteria}

Factors and criteria were defined by the group of specialists. Thanks to the know-how of the Company, ten factors were recommended (1) Productivity, (2) Interferences with other areas, (3) Installation time, (4) Facility of installation, (5) Occupation area, (6) the number of workers, (7) equipment necessary for the movement of earth, and (8) transport of surplus material, (9) the safety factor and (10) the environmental impact factor for noise and dust. The last four factors are very important in order to comply with the COVID-19 protocol, in view that it allows maintaining the distancing of $1.5 \mathrm{~m}$. The last five-factor were not considered in the CBA matrix because the factors and criteria were similar for the three alternatives (Table 1).

Table 1. Matrix factor and Criteria vs Plan of the prevention and control of COVID-19

\section{Factor and Criteria and Protocol COVID-19 (x)}

(1) Productivity: Capable of removing material in a number equal to or greater than 500 m3 / day, to achieve the established term.

(2) Interferences with other areas: That when removing material, it does not interfere with the execution of other planned activities, such as drilling or construction of anchored walls.

(3) Installation time: Short installation time, so as not to have to paralyze the project, or at least not to interfere with the execution of other activities.

(4) Facility of installation: Without needing excess machinery and workers

(5) Occupation area: A system is sought that occupies a small area, to avoid interference in the execution of other activities

\section{Step 3: Summarize the attributes of each alternatives}

In this step, the expert panel summarized the attributes of each alternative based on the specifications of the contractors that provide the removal of surplus material service and with the knowledge and experience of previous projects of the expert panel (see Table 2).

\section{Step 4: Decide advantages of each alternative}

In this step, based on the established criteria, the expert panel identifies the most advantageous alternatives. Table 2 shows a summary of the three alternatives advantages.

\section{Step 5: Decide the importance of each advantages}

In this step, the expert panel collaboratively assigned a level of importance for each advantage. A scale from 1 to 100 was used, giving the value of 100 to the most important advantage and giving lower values to others. Where the supreme advantage is the (5) 
Occupancy area with an IofA of 100, secondly the (2) Interference with other areas and the (3) Installation time with an IofA of 75, and as a third advantage is the (1) Productivity and (4) Facility of installation with an IofA of 50. Once the importances have been assigned to each advantage, the total importance of each alternative is calculated, in such a way that it is easy to compare the alternatives (Table 2).

\section{Step 6: Selection of the alternative with more Importance of the Advantage (IofA)}

In this step, indicators such as importance level are considered in the making-decision. Table 2 shows the CBA analysis with three alternatives solutions to remove the surplus material from basement seven to basement nine. In this step, the importance score of each alternative is summed. It is likely to have tie alternatives due to closing scores, such as the alternative 2 and 3 with scores 295 and 305, respectively.

Table 2: CBA Analysis.

\begin{tabular}{|c|c|c|c|c|}
\hline \multicolumn{5}{|c|}{ Solution alternatives for the removal of material from basement seven to basement nine } \\
\hline 蒫 & Criterion & $\begin{array}{c}\text { ALTERNATIVE 1: } \\
\text { Conveyor belt anchored } \\
\text { in walls }\end{array}$ & $\begin{array}{c}\text { ALTERNATIVE 2: } \\
\text { Conveyor belt without } \\
\text { anchoring in walls + } \\
\text { bucket crane }\end{array}$ & $\begin{array}{l}\text { ALTERNATIVE 3: } \\
\text { vertical lifting system }\end{array}$ \\
\hline \multirow{3}{*}{ 豙 } & \multirow{3}{*}{$\begin{array}{l}\text { Higher } \\
\text { productivity } \\
\text { is better }\end{array}$} & Attribute: $500 \mathrm{~m}^{3} /$ day & Attribute $: 500 \mathrm{~m}^{3} /$ day & Attribute : $600 \mathrm{~m}^{3} /$ day \\
\hline & & Advantage: 0 & Advantage: 0 & Advantage: $100 \mathrm{~m}^{3}$ \\
\hline & & Importance : 0 & Importance : 0 & Importance : 50 \\
\hline \multirow{3}{*}{ 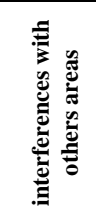 } & \multirow{3}{*}{$\begin{array}{l}\text { Less } \\
\text { interference } \\
\text { is better }\end{array}$} & $\begin{array}{c}\text { Attribute: It hampers } \\
\text { many tasks }\end{array}$ & $\begin{array}{l}\text { Attribute: It hampers a } \\
\text { little some task }\end{array}$ & $\begin{array}{c}\text { Attribute: It almost } \\
\text { does not hamper tasks }\end{array}$ \\
\hline & & Advantage: 0 & $\begin{array}{l}\text { Advantage: It interferes a } \\
\text { bit more than alternative } C\end{array}$ & $\begin{array}{l}\text { Advantage: It is the one } \\
\text { that least interferes }\end{array}$ \\
\hline & & Importance: 0 & Importance: 70 & Importance: 75 \\
\hline \multirow{3}{*}{ 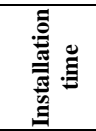 } & \multirow{3}{*}{$\begin{array}{l}\text { Less time is } \\
\text { better }\end{array}$} & Attribute: 14 days & Attribute: 5 days & Attribute: 5 days \\
\hline & & Advantage: 0 & Advantage: 9 days & Advantage: 9 days \\
\hline & & Importance: 0 & Importance: 75 & Importance: 75 \\
\hline \multirow{3}{*}{ 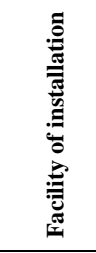 } & \multirow{3}{*}{$\begin{array}{l}\text { Higher } \\
\text { facility is } \\
\text { better }\end{array}$} & $\begin{array}{l}\text { Attribute: this alternative } \\
\text { uses overlaps that make } \\
\text { installation difficult }\end{array}$ & $\begin{array}{l}\text { Attribute: average } \\
\text { difficulty }\end{array}$ & $\begin{array}{l}\text { Attribute: average } \\
\text { difficulty }\end{array}$ \\
\hline & & Advantage a: 0 & $\begin{array}{l}\text { Advantage: the least } \\
\text { difficult }\end{array}$ & $\begin{array}{l}\text { Advantage: the least } \\
\text { difficult }\end{array}$ \\
\hline & & Importance: 0 & Importance: 50 & Importance:50 \\
\hline \multirow{3}{*}{ 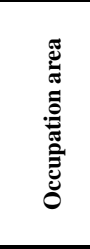 } & \multirow{3}{*}{$\begin{array}{l}\text { Less } \\
\text { area is } \\
\text { better }\end{array}$} & $\begin{array}{l}\text { Attribute: It occupies a } \\
\text { considerable area }\end{array}$ & $\begin{array}{c}\text { Attribute: occupies little } \\
\text { area }\end{array}$ & $\begin{array}{l}\text { Attribute: occupies } \\
\text { little area }\end{array}$ \\
\hline & & Advantage: 0 & $\begin{array}{l}\text { Advantage: it allows more } \\
\text { area available for work }\end{array}$ & $\begin{array}{l}\text { Advantage: it allows } \\
\text { more area available for } \\
\text { work }\end{array}$ \\
\hline & & Importance: 0 & Importance: 100 & Importance: 100 \\
\hline \multicolumn{2}{|c|}{ Score IofA } & 0 & 295 & 305 \\
\hline
\end{tabular}

The experts' panel excluded the alternative one, even if it had a low cost since it presented an IofA of zero. The experts' team concluded that it would present a high probability of non-compliance with the deadline and the COVID-19 protocol. On the other hand, it was observed that alternative 2 obtained a 295 IofA, and alternative 3 obtained 305 . The difference between these two alternatives was $3.38 \%$. The expert panel considered it as a tie since the difference was considered very small for the method used. Thus, the cost factor will determine the winning alternative. 


\section{Step 7: Cost analysis of each alternatives}

A comparative graph of the IofA and the costs of the three alternatives is shown in Figure 5. The cost of each alternative includes the service of rental and maintenance of equipment, payment to workers, earthworks, and transportation of excess material to remove and insurance against accident.

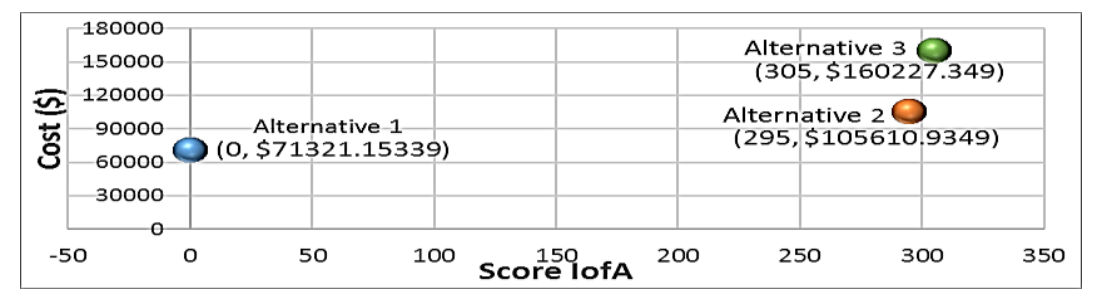

Figure 5. Alternative Costs.

\section{Step 8: Final Decision}

The expert panel determined that alternative 2 was the winner since alternative 3 was $51.7 \%$ higher in cost, and it was only $3.38 \%$ lower in the score obtained in IofA. The first alternative has $30 \%$ less cost, but this was excluded due to the probability of not comply the COVID-19 protocol and the deadline. CBA allowed that the expert team to select the alternative not necessarily the cheapest, but complied with expected performance. CBA helped to exclude one of the alternatives with low cost, but with a high likelihood to not comply with the deadline and the COVID-19 protocol.

\section{IMPLEMENT ALTERNATIVE}

After choosing the alternative, a test was made to observe its performance. Thus, it was observed that the operation of the belt had a cycle time of 1'15"64. It was also verified that the bucket crane efficiently removed large stones that could not be moved through the belt. In general, the task to remove exceeded $400 \mathrm{~m} 3$ per day, so it was always ahead of the other tasks, so it was not a bottleneck in this phase. Figure 6.A and 6.B show the conveyor belt operation, which is not anchored in walls. Figure 6.C shows the bucket crane removal work simultaneously. The panel of experts concluded that if there is no pandemic, they would also use the winning alternative (alternative 2). Since this alternative takes up less space than alternative 1, and allows activities to be carried out in parallel without interruption. In addition, as one of the benefits Parrish and Tommelein (2009) allude, in this study, with the application of CBA it was possible to document and formalize relevant data of the material removal system, making a decision based on important criteria for the context in which the project is located. As well as, speed up the decision-making process.

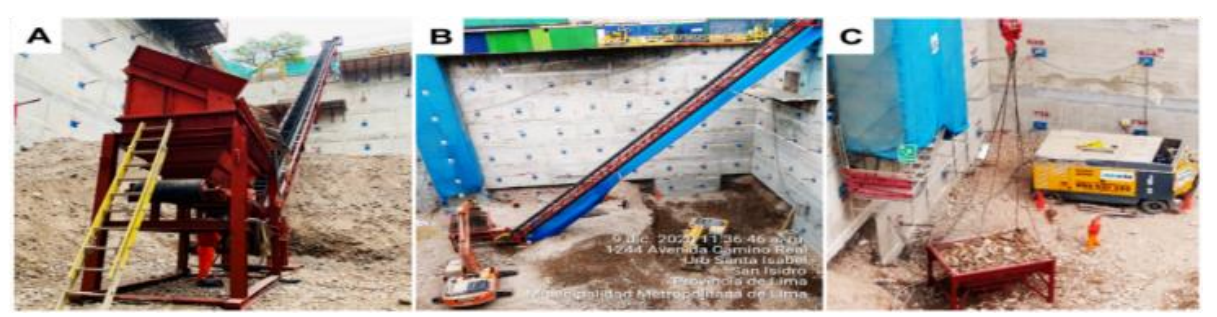

Figure 6. Operation of the conveyor belt and bucket crane. 


\section{CONCLUSIONS}

The main findings of this study were: First, to evidence applying the Choosing by Advantages (CBA) successfully. Second, the evidence that the COVID-19 protocol compliance did not impact the productivity of the project. A practical contribution is the information and important data of the alternatives to choose the best removal system according to the conditions of the project. Given that, this type of construction with several levels of basements has been being carried out with increasing popularity in the city of Lima, which is why it is considered a systematic process. Some of the benefits of CBA that were evidenced are: Allows document and formalize relevant data, making decisions based on important criteria, speed up the decision-making process, allow decide for an alternative that meets with expected performance. The application of CBA presented no barriers since the panel of experts knew the method and it was a collaborative decision. Which differentiates it from other studies, where there are barriers such as resistance to change (Bayhan et al. 2019). Some limitations of the investigation were: First, the application was carried out in a single case study, in a particular company, under unique characteristics, so generalization should be avoided. Second, the factors considered as part of the CBA application are associated with productivity, safety, and compliance with the prevention plan against COVID-19, without considering factors associated with environmental sustainability.

\section{REFERENCES}

Afkhamiaghd, A. M., and Elwakil, E. (2020). "Preliminary modeling of Coronavirus (COVID-19) spread in construction industry." Journal of emergency management (Weston, Mass.), 18(7), 9-17.

Alsharef, A., Banerjee, S., Uddin, S. M., Albert, A., and Jaselskis, E. (2021). "Early Impacts of the COVID-19 Pandemic on the United States Construction Industry." International journal of environmental research and public health, 18(4), 1559.

Arroyo, P., Tommelein, I., \& Ballard, G. (2012). "Deciding a Sustainable Alternative by Choosing by Advantages. In the AEC industry." 20th Annual Conference of the International Group for Lean Construction, San Diego, CA. 41-50.

Arroyo, P., Tommelein, I. D. and Ballard, G. (2013). "Using Choosing by Advantages to Select Tile From a Global Sustainable Perspective." 21th Annual Conference of the International Group for Lean Construction. Fortaleza, Brazil. 309-318.

Arroyo, P., Tommelein, I. D., \& Ballard, G. (2014). "Comparing weighting rating and calculating vs. choosing by advantages to make design choices." 22nd Annu. Conf. Int. Gr. Lean Constr. Vol. 1, No. 510, 1-12.

Bayhan, H. G., Demirkesen, S., \& Jayamanne, E. (2019). "Enablers and barriers of lean implementation in construction projects". IOP Conference Series: Materials Science and Engineering (Vol. 471, No. 2, p. 022002). IOP Publishing.

Brioso, X., Murguia, D., and Urbina, A. (2017). "Comparing three scheduling methods using BIM models in the Last Planner System." Organization, technology \& management in construction: an international journal, 9(1), 1604-1614.

Brioso X., Calderon-Hernandez C., Irizarry J., and Paes D. (2019). "Using Immersive Virtual Reality to Improve Choosing by Advantages System for the Selection of Fall Protection Measures." Comput. Civ. Eng. 2019 Vis. Inf. Model. Simul. - Sel. Pap. from ASCE Int. Conf. Comput. Civ. Eng. 2019, no. June. 146-153, 2019. 
Brioso, X., and Calderón-Hernández, C. (2019). "Improving the Scoring System with the Choosing by Advantages (CBA) elements to evaluate Construction-Flows using BIM and Lean Construction". Advances in Building Education, 3(2), 9-34.

Chauhan, K., Peltokorpi, A., Lavikka, R., and Seppänen, O. (2019). "Deciding between prefabrication and on-site construction: a choosing-by-advantage approach." 27th Annual Conference of the International Group for Lean Construction. 749-758.

Guio S. J., and Cayllahua H. D. (2019). "Análisis de los métodos de eliminación de material para construcción de sótanos en Proyectos que presentan suelo granular en Lima Metropolitana." Research projects. Faculty of engineering, Peruvian University of Applied Sciences, Lima, Peru. (in Spanish).

Juan, R., Jose P., Jose D. and Laura G. (2017). "Choosing by advantages; benefits analysis and implementation in a case study, Colombia." Proc. 26th Annual Conference of the International. Group for Lean Construction, Chennai, India. 636-646.

Karakhan, A., Gambatese, J., and Rajendran, S. (2016). "Application of Choosing By Advantages Decision-Making System to Select Fall-Protection Measures." 24th Ann. Conf. of the Int'l. Group for Lean Construction, Boston, MA, USA, sect.11. 33-42.

Martinez, E., Tommelein, I., \& Alvear, A. (2016). "Formwork system selection using choosing by advantages." In Construction Research Congress 2016 (pp. 1700-1709).

Ministerio de Salud (MINSA). (2020). Resolución Ministerial N 448-2020-MINSA. Lineamientos para la vigilancia, prevención y control de la salud por exposición al SARS-CoV-2. Diario Oficial El Peruano, Lima, Peru. (in Spanish).

Ministerio de Vivienda, Construcción y Saneamiento (MVCS). (2020). Resolución Ministerial No 087-2020-VIVIENDA. Protocolo sanitario del sector vivienda, construcción y saneamiento para el inicio gradual e incremental de las actividades en la reanudación de actividades. Diario Oficial El Peruano, Lima, Peru. (in Spanish).

Perez, C. and Arroyo, P. (2019). "Designing Municipal Waste Management Programs Using Choosing by Advantages and Design Structure Matrix." 27th Annual Conference of the International. Group for Lean Construction, Pasquire C. and Hamzeh F.R. Dublin, Ireland. 1345-1368.

Presidencia del Consejo de Ministros (PCM). (2020). Decreto Supremo No 044-2020PCM. Decreto Supremo que declara Estado de Emergencia Nacional por las graves circunstancias que afectan la vida de la Nación a consecuencia del brote del COVID19. Diario Oficial El Peruano, Lima, Peru. (in Spanish).

Ogunnusi, M., Hamma-Adama, M., Salman, H., and Kouider, T. (2020). “COVID-19 pandemic: the effects and prospects in the construction industry. International journal of real estate studies.", 14(Special Issue 2).

Parrish, K. and Tommelein, I. D. (2009), "Making Design Decisions Using Choosing by Advantages." 17th Annual Conference of the International Group for Lean Construction. Taipei, Taiwan, 15-17 Jul 2009.

Suarez, J. C., Zapata, J., and Brioso, X. 2020. "Using 5D Models and CBA for Planning the Foundations and Concrete Structure Stages of a Complex Office Building." 28th Annual Conference of the International Group for Lean Construction. Berkeley, California, USA.

Suhr. J. (1999). "The choosing by advantages decision making system, Quorum." Greenwood Publishing Group.

World Health Organization. (2020). "WHO characterizes COVID-19 as a pandemic." World Health Organization. 